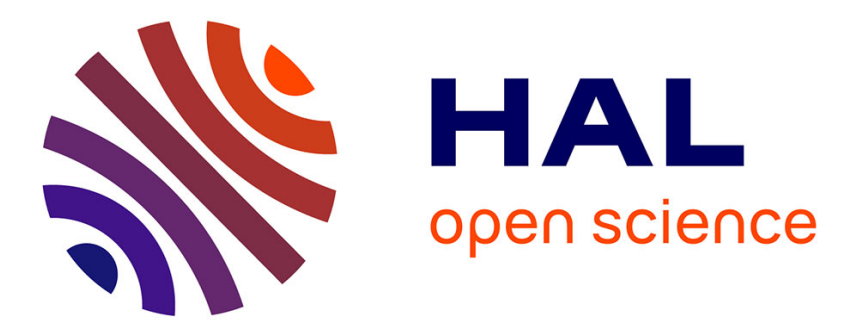

\title{
High temperature electrical transport properties of MBE-grown Mg-doped GaN and AlGaN materials
}

L. Konczewicz, S. Juillaguet, E. Litwin-Staszewska, R. Piotrzkowski, H. Peyre, S. Matta, M. Al Khalfioui, M. Leroux, B. Damilano, J. Brault, et al.

\section{- To cite this version:}

L. Konczewicz, S. Juillaguet, E. Litwin-Staszewska, R. Piotrzkowski, H. Peyre, et al.. High temperature electrical transport properties of MBE-grown Mg-doped GaN and AlGaN materials. Journal of Applied Physics, 2020, 128 (8), pp.085703. 10.1063/1.5140561 . hal-02931592

\section{HAL Id: hal-02931592 \\ https://hal.science/hal-02931592}

Submitted on 25 Nov 2020

HAL is a multi-disciplinary open access archive for the deposit and dissemination of scientific research documents, whether they are published or not. The documents may come from teaching and research institutions in France or abroad, or from public or private research centers.
L'archive ouverte pluridisciplinaire HAL, est destinée au dépôt et à la diffusion de documents scientifiques de niveau recherche, publiés ou non, émanant des établissements d'enseignement et de recherche français ou étrangers, des laboratoires publics ou privés. 


\title{
High Temperature Electrical Transport Properties of MBE-grown Mg-dopedGaN and AlGaN materials
}

\author{
L. Konczewicz ${ }^{1,2}$, S. Juillaguet ${ }^{1}$, E.Litwin-Staszewska ${ }^{2}$, R.Piotrzkowski ${ }^{2}$, H. Peyre ${ }^{1}$, \\ S. Matta ${ }^{1,3}$, M. Al Khalfioui ${ }^{3}$, M. Leroux ${ }^{3}$, B. Damilano ${ }^{3}$, J. Brault ${ }^{3}$ and S. Contreras ${ }^{1,}$ a) \\ ${ }^{1}$ Charles Coulomb (L2C), UMR 5221 CNRS-Université de Montpellier, Montpellier, \\ FR 34-095, France \\ ${ }^{2}$ Institut of High Pressure Physics, Polish Academy of Sciences, Warsaw, PL 01-142, Poland \\ ${ }^{3}$ Université Côte d'Azur, CRHEA-CNRS, Rue Bernard Gregory, 06560 Valbonne, France
}

${ }^{\text {a) Author to whom correspondence should be addressed: sylvie.contreras@umontpellier.fr }}$

\begin{abstract}
This paper discusses the results of high temperature resistivity and Hall effect studies of $\mathrm{Mg}$-doped $\mathrm{GaN}$ and $\mathrm{Al}_{x} \mathrm{Ga}_{1-\mathrm{x}} \mathrm{N}$ epilayers $(0.05<\mathrm{x}<0.23)$. The studied samples were grown by molecular beam epitaxy (MBE) on low temperature buffers of GaN and AIN deposited on sapphire substrate. The experiments were carried out at temperatures ranging from 300 up to $1000 \mathrm{~K}$. Up to certain critical temperature $T_{C}$ (around $800 \mathrm{~K}$ ) a typical increase of the conduction processes due to the excitation of impurity states has been observed with an activation energy of about $E_{A}=200 \mathrm{meV}$. However, at this critical temperature $T_{C}$, an annealing effect was observed in all the investigated samples. At this critical temperature, the increase of the free carrier concentration as a function of time leads to an irreversible decrease of the samples resistivity of more than $60 \%$. The observed temperature dependences of the electrical transport properties are analysed in the frame of an impurity model including shallow donors and Mg-related acceptors (with $E_{A} \sim 200 \mathrm{meV}$ ). In some cases, an additional conduction channel not related to the free carriers in the valence band must be taken into account. This can lead to an incorrect determination of hole concentration in valence band, important parameter in the process of radiative recombination.
\end{abstract}

\section{Introduction}

Nowadays the applications of gallium nitride $(\mathrm{GaN})$ and related compounds-based devices are very broad, from light emitting devices to high power transistors. These applications have continuously increased over the last decade, making nitride materials the second semiconductor market in volume after Si. The p-type doping of nitrides is the key for optical $\left[{ }^{1}\right]$ and electronic $\left[{ }^{2-4}\right]$ devices. Understanding and explaining the properties of point defects in p-type material is crucial for improving the efficiency and longevity of light-emitting and/or power devices based on the GaN $\left.{ }^{5}\right]$. So far, magnesium $(\mathrm{Mg})$ is the only acceptor dopant which generates sufficient p-type conductivity in a reproducible manner. Despite the technological maturity of $\mathrm{GaN}$ devices, there are still some basic properties related to the $\mathrm{Mg}$ doping mechanism and the p-type material behaviors, which are poorly understood, involving many questions. Following the direct lattice location measurements for ion-implanted $\mathrm{Mg}$ in $\mathrm{GaN}$, using the $\beta^{-}$emission channeling technique, it was demonstrated $\left[{ }^{6}\right]$ that the majority of $\mathrm{Mg}$ atoms occupy substitutional $\mathrm{Ga}$ sites. However, significant fractions were also found on interstitial positions, shifted by $\sim 0.6 \AA$ from the ideal octahedral sites. This fraction depends on the $\mathrm{GaN}$ doping character thus giving direct evidence for the amphoteric character of $\mathrm{Mg}$. In the case of metal-organic vapor phase epitaxy (MOVPE), $\mathrm{Mg}$ acceptors are electrically inactive in as-grown material. An additional post-growth treatment is necessary to activate the dopant atoms $\left[{ }^{7}\right]$. This technological step is systematically implemented in MOVPE samples with 
differences between the annealing conditions (temperature, atmosphere) $\left[{ }^{4}\right]$. It is usually accepted that this $\mathrm{Mg}$ activation consists in the dissociation of $\mathrm{Mg}-\mathrm{H}$ complexes [ ${ }^{8}$. In the case of MBE, for which the hydrogen incorporation is much smaller than in MOVPE and the samples are grown at low temperature which decrease the density of the donor like defects $\left[{ }^{9}\right], \mathrm{Mg}$ acceptors are electrically active in the as-grown material and no additional annealing procedure is necessary. It was even pointed out that annealing in an ambient nitrogen environment between $870 \mathrm{~K}$ and $1120 \mathrm{~K}$ for one hour led to no change in the electrical properties of the material grown by Reactive MBE with ammonia $\left[{ }^{10}\right]$. The same effect of electrical active Mg acceptor in the asgrown material was obtained in the case of anothe inherently hydrogen-free growth technique: the low-temperature pulsed sputtering deposition (PSD) process $\left[{ }^{11}\right]$.

In this paper, we present the results of resistivity and Hall effect measurements as a function of temperature on MBE-grown $\mathrm{Mg}$-doped $\mathrm{GaN}$ and $\mathrm{Al}_{\mathrm{x}} \mathrm{Ga}_{1-\mathrm{x}} \mathrm{N}$ layers with $\mathrm{x}$ up to $23 \%$. The experiments have been carried out in the temperature range from $300 \mathrm{~K}$ up to $1000 \mathrm{~K}$. As far as the temperature was lower than a certain critical temperature $T_{C}$ close to $800 \mathrm{~K}$, a typical increase of $p$-type conduction process due to the excitation of acceptor impurity states has been observed $\left[{ }^{10-17}\right]$. Following the literature data, in the case of $\mathrm{GaN}: \mathrm{Mg}$ material, the energy reduction through binding Coulomb interaction between valence-band holes and ionized acceptors takes place $\left[{ }^{14}\right]$. As a result, the effective acceptor energy depth decreases strongly as a function of dopant concentration from 190 to $112 \mathrm{meV}\left[{ }^{15}\right]$ or from 220 to $30 \mathrm{meV}\left[{ }^{16}\right]$ assuming usually an activation energy of $E_{A, 0}=220 \mathrm{meV}$ for isolated acceptors.

For temperatures reaching this critical value $T_{C}$, it was found that the resistivity and Hall effect became time-dependent for all investigated samples. In the case of $\mathrm{GaN}$ samples a more than $60 \%$ irreversible decrease of the sample resistivity as well as an increase of free hole concentration has occurred. In the case of $\mathrm{Al}_{\mathrm{x}} \mathrm{Ga}_{1-\mathrm{x}} \mathrm{N}$ material, the decrease of resistivity is much more pronounced; it decreases by more than one order of magnitude (for $\mathrm{x}=23 \%$ ). The temperature $T_{C}$, characteristic of the annealing process, is dependent on the annealing atmosphere: in presence of oxygen, the annealing effect is more pronounced and occurs at lower temperatures.

\section{Experimental methods}

The materials under study were grown on 2-inch c-plane (0001) sapphire substrates by $\mathrm{MBE}$ in a "Riber 32P" reactor. Effusion cells were used for Ga and Al elements, the Mg dopant was supplied by a RIBER VCOR110 valved cell and ammonia $\left(\mathrm{NH}_{3}\right)$ was used as the nitrogen source. Initially, the substrate surface was nitrided with ammonia at $\sim 950{ }^{\circ} \mathrm{C}$ for $10 \mathrm{~min}$. Then a GaN nucleation layer $(30 \mathrm{~nm})$ was grown at low temperature $\left(\sim 450{ }^{\circ} \mathrm{C}\right)$, followed by a $150 \mathrm{~nm}$ thick AlN layer grown at $950{ }^{\circ} \mathrm{C}$, with a growth rate of $0.1 \mu \mathrm{m} / \mathrm{h}$. This AlN layer was inserted in order to get a compressive strain when growing the p-type $\mathrm{GaN}$ layer and avoid the formation of cracks. Finally, the $\mathrm{Mg}$-doped $\mathrm{GaN}$ or $\mathrm{AlGaN}$ layers were grown at $770{ }^{\circ} \mathrm{C}$, at a growth rate of $0.8 \mu \mathrm{m} / \mathrm{h}$ with a $\mathrm{Mg}$ cell temperature of $270{ }^{\circ} \mathrm{C}$, corresponding to a $\mathrm{Mg}$ atom concentration in the crystals of about $5 \times 10^{19} \mathrm{~cm}^{-3}$.

The concentration of $\mathrm{Mg}$ incorporated in the samples was determined by the secondary ion mass spectroscopy (SIMS) method. The measurements were done using a Cameca IMS $5 \mathrm{f}$ spectrometer with a $\mathrm{Cs}^{+}$primary ion source. The impact energy was $15 \mathrm{keV}$. The secondary beam high voltage was $4.5 \mathrm{kV}$ and the mass resolution was fixed at $\mathrm{M} / \Delta \mathrm{M}=500$. Concerning the $\mathrm{Mg}$ quantification, we applied the $\mathrm{MC}^{+}$method $\left[{ }^{18}\right]$, using relative sensitivity factors (RSFs) derived from the analyses of four well known reference samples (see Table 1). Notice that the first one is a usual $\mathrm{Mg}$ implanted $\mathrm{GaN}$ sample but the three other are $\mathrm{Mg}$ doped $\mathrm{Al}_{\mathrm{x}} \mathrm{Ga}_{1-\mathrm{xN}} \mathrm{N}$ samples grown by MBE, where $\mathrm{x}$ is $0,0.1$ and 0.2 , respectively. These last three samples were previously analyzed by Probion Analysis $\left[{ }^{19}\right]$, which used its own references for the $\mathrm{Mg}$ calibration. The specific detection limit of the investigated atoms was few $10^{16} \mathrm{~cm}^{-3}$. 
Table 1: RSF values, determined from our reference samples, used to calibrate Mg concentration from SIMS analysis.

\begin{tabular}{rccc}
\hline \hline Al content in AlGaN & $\mathbf{0}$ & $\mathbf{0 . 1}$ & $\mathbf{0 . 2}$ \\
\hline $\mathbf{R S F}\left({ }^{133} \mathbf{C s}^{\mathbf{2 4}} \mathbf{M g} /{ }^{133} \mathbf{C s}^{\mathbf{7 1}} \mathbf{G a}\right)$ & $3 \times 10^{22}$ & $1.5 \times 10^{22}$ & $5 \times 10^{21}$ \\
\hline \hline
\end{tabular}

The samples were cut into $5 \times 5 \mathrm{~mm}^{2}$ squares with electrical contacts in van der Pauw configuration at the corners of the sample. The ohmic contacts were formed by the evaporation of $\mathrm{Ni}(20 \mathrm{~nm}) / \mathrm{Au}(200 \mathrm{~nm})$ electrodes and subsequent annealing in $\mathrm{N}_{2}$ ambient at $400{ }^{\circ} \mathrm{C}$. For high temperature measurements and in-situ electrical characterization during annealing, the samples were bonded with gold-wires to a ceramic support. The sample holder was installed in a quartz tube inside a furnace to keep during the high temperature experiments a special atmosphere or a vacuum better then $10^{-6}$ bar. The temperature was measured with a platinum $(\mathrm{Pt})$ resistor and stabilized with a precision better than $1 \mathrm{~K}$.

The resistivity measurements were performed using the van der Pauw method taking the average of all current configurations. Concerning Hall effect measurements, generally, because of high carrier concentrations and low mobilities, to improve the Hall voltage measurements we used the van der Pauw approach $\left[{ }^{20}\right]$ combined with the measurements as a function of the magnetic field $B$ varying between \pm 1 Tesla. Then the Hall carrier concentration was deduced from the slope $\beta$ of the Hall resistance $\rho$ Hall versus $B: \beta=d \rho$ Hall $d B$. As example, on Fig. 1 we plot the $\rho$ Hall $(B)$ results for sample $N$, difficult to measure at a constant magnetic field. During all electrical measurements, the current through the sample was kept adequately low to ensure ohmic conditions.

Fig. 1. Hall effect measurements as a function of magnetic field at $\mathrm{T}=400 \mathrm{~K}$ on sample $\mathrm{N}$ : the slope $d \rho_{\text {Hall }} / d B$ is determined from a least squares fit: $\beta=+2.2 \Omega / \mathrm{T}$ corresponding to the $\mathrm{p}$-type Hall concentration $p_{H}=5.6 \times 10^{18} \mathrm{~cm}^{-3}$ 


\section{Results}

The electrical characteristics of the samples under study are presented in Table 2. Typically, they have been done at temperature $T_{a}$, corresponding to the room temperature. However, in the case of $\mathrm{Al}_{\mathrm{x}} \mathrm{Ga}_{1-\mathrm{x}} \mathrm{N}: \mathrm{Mg}$ mixed crystals with aluminum concentration higher than $15 \%$, a temperature as high as $T_{a}=400 \mathrm{~K}$ was necessary to give well-defined $p$-type characteristics of the samples.

Table 2: Sample characteristics: Al content; SIMS measurements of $\mathrm{Mg}, \mathrm{H}$ and $\mathrm{O}$; resistivity, Hall concentration and Hall mobility measured at $300 \mathrm{~K}$ or $400 \mathrm{~K}$. For $\mathrm{Al}_{\mathrm{x}} \mathrm{Ga}_{1-\mathrm{x}} \mathrm{N}$, a temperature as high as $T a=400 \mathrm{~K}$ was necessary to obtain well-defined p-type characteristics of the material.

\begin{tabular}{|c|c|c|c|c|c|c|c|c|}
\hline \multirow[t]{2}{*}{$\underline{\text { Sample }}$} & \multirow{2}{*}{$\begin{array}{c}\text { Al } \\
(\%)\end{array}$} & \multicolumn{3}{|c|}{ SIMS $\left(1 \times 10^{19} \mathrm{~cm}^{-3}\right)$} & \multirow{2}{*}{$\begin{array}{c}\rho(\mathbf{T}) \\
(\Omega . \mathrm{cm})\end{array}$} & \multirow{2}{*}{$\begin{array}{l}\mathbf{p}_{\mathbf{H}}(\mathbf{T}) \\
\left(\mathrm{cm}^{-3}\right)\end{array}$} & \multirow{2}{*}{$\begin{array}{c}\mu(\mathbf{T}) \\
\left(\mathrm{cm}^{2} / \mathrm{Vs}\right)\end{array}$} & \multirow{2}{*}{$\frac{\mathbf{T}}{(\mathrm{K})}$} \\
\hline & & {$[\mathrm{Mg}]$} & {$[\mathrm{H}]$} & {$[\mathrm{O}]$} & & & & \\
\hline A & 0 & 1.5 & 0.43 & 0.085 & 3.1 & $3.9 \times 10^{17}$ & 5.2 & 300 \\
\hline B & 0 & 1.5 & 0.43 & 0.085 & 7.7 & $2.2 \times 10^{17}$ & 3.7 & \\
\hline $\mathbf{C}$ & 0 & 3.0 & 0.40 & 0.03 & 1.3 & $1.8 \times 10^{18}$ & 2.7 & \\
\hline D & 0 & 3.0 & & & 3.9 & $8.1 \times 10^{17}$ & 2.0 & \\
\hline $\mathbf{E}$ & 0 & & & & 1.3 & $1.9 \times 10^{18}$ & 2.5 & \\
\hline $\mathbf{F}$ & 0 & & & & 5.5 & $2.0 \times 10^{17}$ & 5.7 & \\
\hline $\mathbf{G}$ & 0 & 7.0 & & & 1.2 & $2.5 \times 10^{18}$ & 2.1 & \\
\hline $\mathbf{H}$ & 5 & 3.0 & & & 0.67 & $7.4 \times 10^{18}$ & 1.25 & 400 \\
\hline I & 10 & 2.6 & & & 3.95 & $1.3 \times 10^{18}$ & 1.2 & \\
\hline $\mathbf{J}$ & 13 & 6.0 & & & 4.6 & $6.3 \times 10^{18}$ & 0.22 & \\
\hline $\mathbf{K}$ & 20 & 0.6 & & & 1,96 & $1,9 \times 10^{19}$ & 0.17 & \\
\hline $\mathbf{L}$ & 20 & & & & 2.2 & $1.1 \times 10^{19}$ & 0.26 & \\
\hline $\mathbf{M}$ & 20 & & & & 1.9 & $1.8 \times 10^{19}$ & 0.18 & \\
\hline $\mathbf{N}$ & 23 & & & & 7.0 & $5.6 \times 10^{18}$ & 0.16 & \\
\hline $\mathbf{O}$ & 23 & 3.0 & & & 6.2 & & & \\
\hline
\end{tabular}

On Figure 2, the temperature dependences of resistivity $\rho(1 / T)$ are presented respectively for the GaN:Mg samples B (Fig. 2a) and C (Fig. 2b). The experiments were carried out under vacuum:

- Stage 1 (circles): temperature ramp-up, from $300 \mathrm{~K}$ up to a critical temperature $T c$. For this part of experiment, the measured values are stable as a function of time and only change under effect of temperature variation.

- Stage 2 (circles): in situ measurement of the evolution as a function of time of electrical parameters of sample placed at constant temperature $T=T c$. Temperature is maintained at Tc until the monitored electrical parameters stabilize.

- Stage 3 (squares): temperature ramp-down, after annealing, from $T c$ down to $300 \mathrm{~K}$. For this part of experiment, the measured values are once more stable as a function of time.

With increasing temperature, as long as it remains lower than some critical values $T_{C}$, the resistivity of the samples decreases revealing thermally activated conduction processes. At a temperature $T_{C}$, the electrical transport parameters of the samples become time-dependent and 
the resistivity decreases as a function of time. For all $\mathrm{GaN}: \mathrm{Mg}$ samples ( $\mathrm{A}, \mathrm{B}, \mathrm{C}$ and $\mathrm{D}), T_{C}$ is approximatively equal to $880 \mathrm{~K}$.

Fig. 2. Variation of resistivity $\rho$ vs reciprocal temperature for samples B (Fig. 2a) and C (Fig. 2b): circles (i) $\rho$ up to a critical temperature $T_{C}$ and (ii) at $T_{C}, \rho$ evolves as function of time until stabilization; diamonds-after annealing, from $T_{C}$ down to $300 \mathrm{~K}$; stars on the Fig. $2 \mathrm{~b}$ correspond to the second temperature run after the annealing process. The arrows help to guide the eyes according to the sense of changes of temperature during the experiment. The critical temperature is $T_{C}=880 \mathrm{~K}$.

A typical example of the resistivity changes as a function of time at annealing temperature $T_{C}$ is presented for sample B on the Fig. 3. After about one hour of isothermal annealing, the sample resistivity tends to some saturation value, which corresponds approximatively to $60 \%$ of the initial one. As soon as the resistance has become practically independent of time, once again the resistivity was measured as a function of temperature in the decreasing variation.

Fig. 3. Resistivity of sample $B$ as a function of time for an annealing at $T=880 \mathrm{~K}$

Two types of resistivity versus temperature dependence were observed. In the case of sample B (Fig. 2a) and A, as a result of the annealing, the resistivity decreased and retained, after return to room temperature, the offset imposed by the annealing: the final value, at room temperature, is still about $60 \%$ lower than the initial one. In the case of sample C (Fig. $2 \mathrm{~b}$ ) and $\mathrm{D}$, even if the permanent change of resistivity at high temperature is also about $60 \%$, then a subsequent increase of $\rho(1 / T)$ after annealing is more abrupt and as a result, the final resistivity value, at room temperature, is practically the same as the initial one. Consequently, for these samples the resistance measured at room temperature reveals no effect of the annealing at high temperature. It should be noticed that the observed changes on the temperature dependence of resistivity are permanent as shown in Fig. $2 \mathrm{~b}$ (star labels) after the second temperature cycle on sample C.

The changes of material parameters as a function of temperature and high temperature annealing were also studied by Hall effect measurements, as plotted in Figure 4. The Hall concentrations versus reciprocal of temperature have been measured for samples $\mathrm{A}$ and $\mathrm{B}$. The Hall concentration of holes were calculated from the simple relation $p_{H}=1 / e R_{H}$ where $e$ correspond to the electron charge and $R_{H}$ to the experimentally determined Hall constant. It is evident that the changes of the carrier concentration with temperature follows the effects observed for resistivity. Initially the holes concentration increases as a function of temperature according to the thermally activated conduction process. In the same way, the high temperature annealing process corresponds to the increase of free carrier concentration.

Fig. 4. Variation of Hall concentration vs reciprocal temperature for sample A (Fig. 4a) and B (Fig. 4b): circles correspond to $p_{H}=1 /\left(e R_{H}\right)(1 / T)$ dependence before annealing and diamonds-after annealing; Arrows help to guide the eyes according to of the increasing or decreasing temperature variation during the experiment

Fig. 5 shows the time dependence of Hall mobility $\mu_{H}=\sigma R_{\mathrm{H}}$ measured on sample $\mathrm{B}$ and $\mathrm{D}$ at $\mathrm{T}=880 \mathrm{~K}$. The high temperature annealing process leads to a very slight but undoubted 
increase of Hall mobility. In any case, the mobility increases in the initial phase of annealing and then is practically independent of time.

In the case of $p$-type GaN:Mg material grown by MOVPE, it has been shown that the presence of oxygen in the annealing environment can affect the activation process $\left[{ }^{21,22}\right]$. To check whether the observed annealing process depends on the conditions in which it is carried out, an additional experiment was done under air atmosphere. It was carried out on sample E, derived from the same wafer as sample C. Results are presented on Figure 6. The character of resistivity variation with temperature is very similar to the sample $\mathrm{C}$ one (Fig. 2b). The same similarity between both experiments can be also observed in Hall effect measurements. However, the temperature of the annealing phenomenon under air $\left(T_{\text {cair }}=780 \mathrm{~K}\right)$ is distinctly lower than the previous value $\left(T_{C v a c}=880 \mathrm{~K}\right)$ measured in vacuum.

Fig. 5. Hall mobility versus time dependence at $\mathrm{T}=880 \mathrm{~K}$ for samples $\mathrm{B}$ (diamonds) and $\mathrm{D}$ (circles).

Fig. 6. Variation of resistivity vs reciprocal temperature for samples $\mathrm{C}$ and $\mathrm{E}$ respectively: circles correspond to sample $\mathrm{C}$ annealed in vacuum and diamonds to sample $\mathrm{E}$ annealed in air. The temperature of the annealing phenomenon under air is distinctly lower than the previous experiment in vacuum $(780 \mathrm{~K}$ instead $880 \mathrm{~K})$.

The conditions of previously described experiments do not allow the precise and quantitative control of the annealing conditions. Consequently, an additional series of experiments was realized in a Rapid Thermal Annealing (RTA) system allowing controlling the annealing atmosphere and temperature. However, in the case of RTA, it is impossible to study the annealing process by in-situ measurements of electrical transport properties. Therefore, for this study, a series of samples was prepared. These samples, labelled F, come from the same growth process as sample A. The as-grown samples were annealed as a function of time in two different atmospheres $\left(\mathrm{N}_{2}\right.$ and $\left.\mathrm{N}_{2}+20 \% 0_{2}\right)$ at different temperatures $(700 \mathrm{~K}, 750 \mathrm{~K}, 800 \mathrm{~K}$ and $870 \mathrm{~K})$. After the process, a post-annealing characterization of each sample has been done at room temperature. Results of resistivity measurements are presented in Fig. 7. A similar behavior was observed in the case of Hall effect measurements. An annealing process carried out under nitrogen atmosphere, even at temperature as high as $870 \mathrm{~K}$, does not cause any significant change in resistivity or carrier concentration values at room temperature. But the presence of a mixture of nitrogen and $20 \%$ of oxygen causes a distinct decrease in resistance (and accordingly an increase in carrier concentration) already with an annealing temperature of $750 \mathrm{~K}$. The increase of annealing temperature up to $800 \mathrm{~K}$ does not cause any noticeable changes in the efficiency of the annealing process.

Fig. 7. Room temperature resistivity of the sample series $\mathrm{F}$ as a function of thermal annealing duration at different temperatures: a) at $700 \mathrm{~K}$, b) at $750 \mathrm{~K}$ and c) at $800 \mathrm{~K}$. Squares and circles correspond respectively to annealing under $\mathrm{N}_{2}$ and $\mathrm{N}_{2}+20 \% \mathrm{O}_{2}$ atmosphere. Stars on Fig. 7c correspond to the annealing process at $870 \mathrm{~K}$ under $\mathrm{N}_{2}$ atmosphere. The dashed lines help to guide the eyes

As aluminum-rich materials are important for ultraviolet applications, we extended our research to $\mathrm{Al}_{\mathrm{x}} \mathrm{Ga}_{1-\mathrm{x}} \mathrm{N}: \mathrm{Mg}$ compounds with aluminum content up to $23 \%$. On Figure 8, the temperature dependences of resistivity $\rho(1 / T)$ are plotted respectively for two samples with different Al content: sample I ( $x=10 \%$; Fig. 8a) and $\mathrm{K}(x=20 \%$; Fig. 8b). The experiments were carried out under vacuum. The observed $\rho(1 / T)$ dependencies are analogous to those observed in $\mathrm{GaN}$ samples. With increasing temperature, as long as it remains lower than some critical value 
$T_{C}$, the sample resistivity decreases revealing a thermally activated conduction processes. At temperature as high as $T_{C}$, the electrical transport parameters become time-dependent and the value of resistivity decreases. Also, the return to ambient temperature is similar to that observed in GaN:Mg. The resistance decrease, generated at high temperature during the annealing process, is either preserved down to room temperature (sample I; Fig. 8a) or deleted when decreasing the temperature. In this last case, the resistance value at room temperature is close to the initial one (sample K; Fig. 8b). For the presented samples, the critical temperatures $T_{C}$, in which the annealing process occurs, are higher than in the GaN case and are different among each other. Moreover, the experiments performed on samples with different aluminum content (samples from $\mathrm{H}$ to $\mathrm{O}$ ) have confirmed different $T_{C}$ values, which are between 730 and $920 \mathrm{~K}$. However, these different $T_{C}$ values cannot be related to sample parameters: either the Al composition or doping level.

To verify the influence of the annealing atmosphere, similar to the case of GaN, two annealing experiments were carried out for two samples originated from the same growth process: for the sample $\mathrm{L}$ the experiment was carried out under air and for the sample $\mathrm{M}$ under vacuum. Comparison is done in Fig. 9. The character of resistivity variation with temperature for both samples is very similar. However, as in $\mathrm{GaN}$, the temperature $T_{C}$ of the annealing phenomenon under air is $100 \mathrm{~K}$ lower than the one observed for annealing under vacuum.

Fig. 8. Variation of resistivity vs reciprocal temperature for $\mathrm{Al}_{\mathrm{x}} \mathrm{Ga}_{1-\mathrm{x}} \mathrm{N}$ samples: (a) sample I with $\mathrm{Al}$ composition $x=10 \%$ and (b) sample $\mathrm{K}$ with $\mathrm{Al}$ composition $x=20 \%$. Circles correspond to $\rho(1 / T)$ dependence before annealing and diamonds-after annealing; The annealing temperatures are respectively $T_{C}=910 \mathrm{~K}$ for sample I and $T_{C}=904 \mathrm{~K}$ for sample $\mathrm{K}$

Fig. 9. Variation of resistivity $v s$ reciprocal temperature for samples $\mathrm{L}$ and $\mathrm{M}$ : circles correspond to experiment carried out under vacuum (sample $\mathrm{M}$, the annealing temperature $T_{C}=920 \mathrm{~K}$ ) and diamonds to experiment carried out under air (sample $\mathrm{L}$, the annealing temperature $T_{C}=820 \mathrm{~K}$ ).

Fig. 10. Changes of resistivity $v s$ time during the annealing under vacuum at temperature $\mathrm{T}_{\mathrm{C}}$. Results for GaN (sample $\mathrm{E}$ ) and ternary $\mathrm{Al}_{\mathrm{x}} \mathrm{Ga}_{1-\mathrm{x}} \mathrm{N}$ compounds with aluminum composition respectively: $x=5 \%$ (sample $\mathrm{H}$ ); $x=13 \%$ (sample $\mathrm{J}$ ) and $x=23 \%$ (sample $\mathrm{O}$ ).

Resistivity at $T_{C}$ versus time dependency for different samples are plotted in Fig. 10. In all cases, the resistance decreases as a function of time and tends to some saturation value which is evidently dependent on the $\mathrm{Al}$ content. The time necessary to achieve this value is quite long, of the order of few hours. In GaN, the final value is approximately $60 \%$ of the initial one, whereas in the case of $\mathrm{Al}_{\mathrm{x}} \mathrm{Ga}_{1-\mathrm{x}} \mathrm{N}$ compound with an aluminum content of $23 \%$, the resistance during annealing decreases by more than one order of magnitude.

\section{What is going on?}

From the most general point of view, to discuss the effect of temperature on the concentration of holes in the valence band, the intrinsic excitation of carriers and presence of different donor and acceptor centers should be taken into consideration. The intrinsic carrier concentration, even at temperatures as high as $1000 \mathrm{~K}$, remains negligibly low (lower than $1 \times 10^{13} \mathrm{~cm}^{-3}$ ) owing to the large band gap of the material. This means that the holes in the valence band come only from the acceptor states partially compensated by electrons from the donor 
states, which are completely ionised. Thus, the charge-neutrality conditions of the crystal can be written as:

$$
p+N_{D}^{(+)}=\sum_{i} N_{A i}^{(-)}=\sum_{i} \frac{N_{A i}}{1+g_{i} \exp \left(\frac{E_{A i} E_{f}}{k_{B} T}\right)}
$$

where $k_{B}$ is the Boltzmann constant, $T$ is the temperature, $p$ is the free hole concentration in the valence band, $N_{D}^{(+)}=N_{D}$ is the total concentration of compensating donors and $N_{A i}^{(-)}$the concentration of acceptor centers (i) occupied by electrons. The acceptor states $(i)$ are characterised by an activation energy $\left(E_{A i}\right)$, their concentration $\left(N_{A i}\right)$ and degeneracy $g_{i}$. Concerning shallow donors, the degeneracy $g=1 / 2$ is commonly admitted. However, even in the case of shallow acceptors, the situation is more complicated due to contributions from $s$-like and $p$-like states as well as the degeneracy of the valence band. In our analysis, acceptor degeneracy is assumed equal to 4 , as usual for shallow acceptors.

To determine the parameters of acceptor and donor impurities from electrical transport measurements, a large part of published results is based only on the fitting of the Hall concentration $\left[{ }^{11},{ }^{15},{ }^{23}\right]$. However, to attempt modeling free carriers concentration following the formula of charge-neutrality conditions (1) and to converge towards a unique solution, simultaneously $p_{H}$ and $\mu_{H}$ fitting must be performed. These simultaneous fits need a combination of temperature-dependent hole concentration and temperature-dependent hole mobility with hole scattering theory. This is difficult to do because of the complexity of the valence band and the coupling between the heavy-hole and light-hole states (not mentioning the split-off valence band, which can also be populated at high T). Consequently, the precise quantitative analysis of the Hall effect requires the use of a multi-carriers model of conduction taking into account the presence of heavy and light holes, as well as the corresponding mobilities and scattering factors $r$. In addition, for high doping levels and large temperature domains, usual models for mobility calculation must be handled with care. For this reason and to allow our results to be compared with most of the available analysis in the literature, a simplified model with a single valence band characterized by a density of states effective mass of $m_{v}=1.5 m_{o}\left[{ }^{24}\right]$ was considered in our analysis. Based on the results of a meticulous analysis of transport results in medium-doped samples $\left[{ }^{23}\right]$, it leads to the underestimated value of Hall holes concentration compared to the real total concentration of light and heavy holes.

Even in the simple model assuming the conduction mechanism by only one type of carriers, the experimentally measured Hall concentration $\left(p_{H}\right)$ and Hall mobility $\left(\mu_{H}\right)$ differ from the hole concentration in the valence band $(p)$ and the carrier mobility $(\mu)$ respectively by the Hall scattering factor, $r_{H}$ :

$$
p_{H}=\frac{1}{e \times R_{H}}=\frac{p}{r_{H}} \quad \text { and } \quad \mu_{H}=R_{H} \times \sigma=r_{H} \mu
$$

In the following, we assume $r_{H}=1$ and in this case, the hole concentration and the carrier mobility correspond directly to the measured Hall concentration and Hall mobility, respectively.

At high temperatures $\mathrm{T} \geq 400 \mathrm{~K}$, the observed character of $p_{H}(T), \rho(T)$ dependences and the values of electrical parameters for the complete $\mathrm{GaN}: \mathrm{Mg}$ sample series are very similar. Nevertheless, the temperature behavior can be quite different near room temperature (Fig. 2, samples B and C). While the character of $\rho(T)$ dependency for sample B does not change down to room temperature, for sample $\mathrm{C}$, this dependency tends to saturation. We thus distinguish two types of characteristic behavior for two sets of GaN samples: samples A, B (series 1) and samples C, D, E (series 2). Similar behaviors near room temperature were observed for AlGaN samples (see on Fig. 8 respectively results for samples I and K). For this reason, the analysis of 
the experimental results will be done separately for each set of samples. However, as mentioned above, because of the limitations of the theoretical model, the additional information could not reliably be garnered from Hall mobility measurements. Consequently, in compensated semiconductor, there is no unique solution with this fitting procedure where the extracted parameter values $E_{A}, N_{A}$ and $N_{D}$ are interdependent.

To explain the experimentally observed high temperature annealing effect, i.e. the increase of hole concentration versus time, two mechanisms are possible: i) the increase of the number of active acceptors and/or ii) the decrease of the number of compensating donors.

As already mentioned, $\mathrm{Mg}$ as active acceptor requires its incorporation on the substitutional $\mathrm{Ga}$ site $\left(\mathrm{MgGa}_{\mathrm{G}}\right)$. On other sites as interstitial, replacing $\mathrm{N}$ or complexes with $\mathrm{H}(\mathrm{Mg}$ $\mathrm{H}), \mathrm{O}(\mathrm{Mg}-\mathrm{O})$ and vacancies $\left(\mathrm{Mg}-\mathrm{V}_{\mathrm{N}, \mathrm{Ga}}\right)$, it should be electrically inactive or even exhibit a donor character. Recall that in $\mathrm{GaN}$ the mains donors are oxygen on a nitrogen site $\left(\mathrm{O}_{\mathrm{N}}\right)$, silicon on a $\mathrm{Ga}$ site $\left(\mathrm{Si}_{\mathrm{Ga}}\right)$, and the $\mathrm{N}$ vacancy $\left(\mathrm{V}_{\mathrm{N}}\right)$.

First, concerning the increase of active acceptors, the high temperature activation of $\mathrm{Mg}$ centers, related to the dissociation of $\mathrm{Mg}-\mathrm{H}$ complexes is an obvious mechanism evidenced in MOVPE growth samples. However according to the litterature $\left.{ }^{25}\right], \mathrm{Mg}-\mathrm{H}$ complexes are negligible in MBE samples. Moreover, this thermally activated process takes place below $700 \mathrm{~K}\left[{ }^{26}\right]$, at temperature much lower than the observed experimentally critical temperatures $T_{C}$ higher than $800 \mathrm{~K}$. It should also be noted that during the dissociation of $\mathrm{Mg}-\mathrm{H}$ complexes the hydrogen ions could migrate to the surface. Therefore SIMS measurements before and after the heating process could provide relevant information to explain the process that occurs during annealing. However the SIMS results presented on Figure 11 indicate that a precise analysis of hydrogen content in the sample is difficult because the hydrogen concentration changes according to the time spent in SIMS apparatus under high vacuum condition, at room temperature. Even if the quantitative analysis cannot be precisely done, one can observe the pronounced decrease of hydrogen concentration in the sample as a function of time: the change of its profile across the sample indicates that this element desorbs under vacuum condition.

Fig.-11. Hydrogen concentration profile in sample B from SIMS analysis carried out in some day's interval. All the time, sample was kept in SIMS apparatus under high vacuum condition at room temperature.

Other candidates for increasing the concentration of electrically active magnesium acceptors can be the dissociation of complexes: $\mathrm{Mg}-\mathrm{O}\left[{ }^{27}\right]$ and $\mathrm{Mg}-\mathrm{V}_{\mathrm{N}}$. The SIMS analyses (Table 2) indicate that the oxygen concentration in the investigated samples is not high enough to play a significant role in the annealing process. However, in the case $\mathrm{Mg}-\mathrm{V}_{\mathrm{N}}$ complexes the thermal annealing at temperatures higher than $800 \mathrm{~K}$ could lead to their dissociation and to activation of supplementary $\mathrm{Mg}$-acceptor centers $\left[{ }^{25}\right]$.

The second explanation of the observed effects may be related to the reduction in the degree of compensation in the material. From theoretical as well as experimental considerations, nitrogen vacancies $\mathrm{NV}_{v}$ and $\mathrm{Mg}-\mathrm{N}_{v}$ complexes are the dominant compensating centers in MBE samples when $\mathrm{Si}$ and $\mathrm{O}$ impurities can be neglected. However there is still an open question concerning the role of $\mathrm{H}$ as an isolated atom. It is generally assumed that it acts as an amphoteric impurity. In the case of $p$-type $\mathrm{GaN}$ with the Fermi level $E_{F}$ locating close to the valence band maximum, the positive charged $\mathrm{H}^{+}$is stable and $\mathrm{H}$ acts as a donor $\left.{ }^{28}\right]$. The migration barrier for positively charged hydrogen is sufficiently small $\left(0.7 \mathrm{eV}\left[{ }^{29}\right]\right)$ to ensure the high mobility of $\mathrm{H}^{+}$ions. Hydrogen ions could migrate to the surface or to extended defects (dislocations). By this way, they can be removed or neutralized, respectively. In the case of $\mathrm{H}^{+}$migration at temperatures higher than $800 \mathrm{~K}$, an additional and efficient process of hydrogen-ion neutralization appears due 
to the creation of $\mathrm{Ga}$ vacancies $\left.\left(\mathrm{V}_{\mathrm{Ga}}\right){ }^{30}\right]$. For extremely $p$-type conditions, the formation energy of $\mathrm{V}_{\mathrm{Ga}}$ or $\mathrm{V}_{\mathrm{Ga}} \mathrm{H}$ complexes is quite high. From the kinetic point of view $\mathrm{V}_{\mathrm{Ga}} \mathrm{H}_{2}$ complex is most likely to form. It should also be pointed out that following reference $\left[{ }^{30}\right]$, the oxygen atmosphere plays an important role in the Ga vacancies formation. Consequently, this model would allow explaining the impact of the atmosphere in the annealing process and the differences observed when experiments are realized under air or in presence of oxygen (RTA experiments). It is generally assumed that the higher aluminum contents correspond to higher concentration of oxygen in the samples $\left[{ }^{31},{ }^{32}\right]$, so it can also explain the annealing effect on AlGaN samples with different Al content (Fig. 10). Indeed, the effect of annealing increases significantly with the composition of aluminum. Hull et al. $\left[{ }^{21}\right]$ also emphasized the role of oxygen in the activation process, which enhances the removal of $\mathrm{H}$ that passivates the $\mathrm{Mg}$ atoms. It is worth noticing that the adoption of the model in which the annealing leads to a reduction of compensating donors means that during annealing, the concentration of ionized centers in the sample decreases. In this way, the scattering on the ionized impurities center become less efficient which is in agreement with the experimentally observed increase of mobility during annealing process (Fig. 5).

On Fig. 12, the results of our fitting procedure are discussed in the case of the $p_{H}(T)$ dependence for sample A (series 1). It has been done for three different compensation levels. Before annealing, (solid red lines in Fig. 12) the compensation degree was respectively, with $K=N_{D} / N_{A}$ : no compensation $(K=0)$; low compensation $K=7.7 \%$ and medium compensation $K=20 \%$. The fitting parameters are summarized in Table 3 (called initial parameters). We observe a better agreement with the experimental results by increasing the compensation ratio. In addition, it should be noted that for $K=0$, the deduced acceptor ionization energy $\left(E_{A}\right)$ is higher than the expected value for the $\mathrm{Mg}$ level in GaN. After annealing, to explain the experimental effect, we consider separately two possible effects: the increase of $N_{A}$ ( $N_{D}$ remaining constant) or the decrease of $N_{D}\left(N_{A}\right.$ remaining constant $)$. Whatever the compensation level, we have a good agreement between the experimental and fitted data and the annealing effect can be related to an increase of active acceptor concentration (Table $3-N_{D}=\mathrm{C}^{\mathrm{t}}$, green dash dot lines in Fig.12). The decrease of $N_{D}$ only makes sense in the case of $K=20 \%$ (Table $3-N_{A}=\mathrm{C}^{\mathrm{t}}$, blue short dash line in Fig. 12c). Both fitting curves are practically identical and the fitting procedure does not allow discerning which hypothesis is more appropriate.

It should be noted that regardless of the degree of compensation adopted, the values of acceptor concentration $N_{A}$ necessary as a fitting parameter are significantly higher than the concentration of $\mathrm{Mg}$ atoms determined from SIMS measurements. This statement corresponds to a more general observation: assuming Hall coefficient $r_{H=1}$ leads to a systematic overestimation of the doping level in the matching procedure. Similar results are obtained in other wide band gap semiconductors as $p$-type $\mathrm{SiC}\left[{ }^{33},{ }^{34}\right]$ where the estimated acceptor density could exceed the chemical density of the $\mathrm{Al}$ acceptor impurities and in the modeling of transport properties a semi-empirical $r^{*}{ }_{H}$ parameter is used $\left[{ }^{35}\right]$.

Fig. 12. The $p_{H}(T)=1 /\left(e R_{H}\right)$ fitting procedure for sample $\mathrm{A}$. The calculations have been done for three compensation levels: a) no compensation $(K=0)$; b) low compensation $K=7.7 \%$ and c) medium compensation $K=20 \%$. The fitting parameters are summarized in Table 3.

Concerning sample B, it has a carrier concentration nearly twice lower than sample A (Table 2). However, it is characterized by a lower mobility. This means that it is more compensated. This is confirmed by the results plotted on Figure 13 where the best fit is obtained with a compensation ratio $K=50 \%$ (see the parameters in Table 3 ). As in sample A, for results after annealing, the fitting procedure does not allow discerning which parameters are more 
appropriate: the increase of $N_{A}$ or the decrease of $N_{D}$. Probably both $N_{A}$ and $N_{D}$ play a role in the annealing effect.

Table 3: Fitting parameters used for modeling free carriers concentration following the formula of charge-neutral conditions (1) for samples A and B (series 1).

\begin{tabular}{|c|c|c|c|c|c|}
\hline Sample & \multicolumn{3}{|c|}{ Initial parameters (before annealing) } & \multicolumn{2}{|c|}{ Final parameters (after annealing) } \\
\hline \multirow[t]{3}{*}{ Series 1} & & & & $\begin{array}{c}\text { Hypothesis } \\
N_{D}=\mathrm{C}^{\mathrm{t}}\end{array}$ & $\begin{array}{c}\text { Hypothesis } \\
N_{A}=\mathrm{C}^{\mathrm{t}}\end{array}$ \\
\hline & $\begin{array}{c}K=N_{D} / N_{A} \\
(\%)\end{array}$ & $\begin{array}{c}E_{A} \\
(\mathrm{meV})\end{array}$ & $\begin{array}{c}N_{A \text { initial }} \\
\left(\times 10^{20} \mathrm{~cm}^{-3}\right)\end{array}$ & $\begin{array}{l}N_{A \text { after annealing }} \\
\left(\times 10^{20} \mathrm{~cm}^{-3}\right)\end{array}$ & $\begin{array}{l}N_{D \text { after annealing }} \\
\left(\times 10^{20} \mathrm{~cm}^{-3}\right)\end{array}$ \\
\hline & 0 & 280 & 5.5 & $2.4 \times N_{A \text { initial }}$ & - \\
\hline \multirow[t]{2}{*}{$\mathbf{A}$} & 7.7 & 155 & 1.3 & $1.5 \times N_{A \text { initial }}$ & - \\
\hline & 20 & 126 & 5 & $1.4 \times N_{A \text { initial }}$ & $0.7 \times N_{D \text { initial }}$ \\
\hline B & 50 & 104 & 1.5 & $1.3 \times N_{A \text { initial }}$ & $0.7 \times N_{D \text { initial }}$ \\
\hline
\end{tabular}

Fig.13. The $p_{H}(T)=1 /\left(e R_{H}\right)$ fitting procedure for sample B. The calculations have been done for a compensation level $K=50 \%$. The fitting parameters are summarized in Table 3 .

Concerning the series 2: for samples C, D and E, as already mentioned earlier, the electrical parameters at high temperature are very similar to sample A. However, near room temperature, the saturation of both $p_{H}(T)$ and $\rho(T)$ is observed which leads, at room temperature, to i) an apparent Hall carrier density higher than the hole valence band concentration value predicted by the model of $\mathrm{Mg}$-acceptor state and ii) a low resistance. As an example, the results of fitting procedure of the $p_{H}(T)$ dependence for sample $\mathrm{E}$ are presented on Fig. 14. While it is possible to match the experimental results in the high temperatures range $\mathrm{T}>400 \mathrm{~K}$, it would be necessary to adapt the unrealistic parameters of an additional shallow acceptor level to explain the $p_{H}(T)$ behavior near room temperature. Results on Fig. 14 are strikingly similar to the ones presented by Lancefield et al. $\left[{ }^{36}\right]$ and Kozodoy et al. $\left[{ }^{[5]}\right.$ where the saturation, observed at lower temperature, is related to the hopping conductivity in an impurity band (IB). The observation of an IB conduction at room temperature and above is not usual but it has been seen in $p$-type $4 \mathrm{H}$ $\mathrm{SiC}\left[{ }^{37}\right]$ owing to the high thermal ionization energy of the $\mathrm{Al}$ acceptors. In GaN, the thermal ionization energy for $\mathrm{Mg}$ acceptor is comparable to the $\mathrm{Al}$ one in $\mathrm{SiC}$. Therefore, the very evident saturation effect might result from a competitive conduction mechanism in the impurity band that adds to the conduction process in the valence band.

Fig. 14. Variation of Hall concentration vs reciprocal temperature for sample E: circles correspond to $p_{H}=1 / e R_{H}$ measured experimentally and solid lines to the fitting curves with the following fitting parameters: $\mathrm{E}_{\mathrm{A}}=109 \mathrm{meV}$, initial parameters (before annealing):

$N_{D}=3.0 \times 10^{18} \mathrm{~cm}^{-3}$

$N_{A}=2.5 \times 10^{19} \mathrm{~cm}^{-3}$

Final parameters (after annealing):

$N_{D}=9.5 \times 10^{18} \mathrm{~cm}^{-3}$

$N_{A}=7.0 \times 10^{19} \mathrm{~cm}^{-3}$ 
From Fig. 14, we can draw the following conclusions:

1. Considering the second conducting channel in the impurity band, the observed change in the resistivity and carrier concentration versus temperature dependence near room temperature can be explained. As a result, the values of mobility and carrier concentration determined at room temperature are only apparent Hall density and Hall mobility which are different than the hole valence band concentration and mobility, respectively.

2. The influence of the second conductive channel may interfere with Hall effect measurements throughout the whole high temperature range. This can lead to incorrect determination of the energy of the acceptor level $E_{A}$ as a fitting parameter of the $p_{H}(T)$ dependency even in a very wide temperature range study.

The results of the resistivity measurements also encounter difficulties in interpretation since a usually "low temperature-hopping phenomenon" can influence the conductivity even at higher temperature. In this case, it is difficult to interpret the conductivity and its temperature dependence whatever the temperature.

\section{Conclusions}

In this paper, the results of high temperature resistivity and Hall effect measurements of Mg-doped GaN and AlGaN epilayers grown by MBE have been presented. At temperatures close to $800 \mathrm{~K}$, an annealing process is observed in all the investigated samples. It leads to an irreversible decrease of sample resistivity related to the increase of the free carrier concentration. In the presence of oxygen, the observed effect is more pronounced. The observed annealing effects are most likely related to a decrease of the compensation, i.e. a decrease of the donor concentration, specifically hydrogen ions. At temperatures higher than $800 \mathrm{~K}$, due to the creation of Ga vacancies, an efficient process of hydrogen-ion neutralization takes place. In the presence of oxygen in the annealing atmosphere, the observed effect is more pronounced and takes place at a lower temperature range $(\mathrm{T}<800 \mathrm{~K})$.

We have demonstrated that high temperature studies are important to confirm the validity of the electrical parameters of $\mathrm{Mg}$-doped $\mathrm{GaN}$ or $\mathrm{AlGaN}$ layers determined at room temperature. In extreme p-type doping conditions, an additional conduction channel not related to the free carriers in the valence band could add to the conduction process and consequently the room temperature electrical parameters of the doped material can be determined erroneously. In particular, this concerns the concentration of holes in the valence band, an important parameter in the process of radiative recombination.

\section{Acknowledgments}

This work was supported by the ANR Project (No. ANR-14-CE26-0025) "NANOGANUV." The authors also acknowledge support from the GANEX (No. ANR-11-LABX-0014). GANEX belongs to the publicly funded "Investissements d'Avenir" program managed by the French ANR agency.

\section{Data Availability}

The data that support the findings of this study are available from the corresponding author upon reasonable request. 


\section{References}

${ }^{1}$ S. Nakamura, S. Pearton, and G. Fasol, The Blue Laser Diode the Complete Story (2010).

${ }^{2}$ A. Krishna, A. Raj, N. Hatui, S. Keller, and U.K. Mishra, Appl. Phys. Lett. 115, 172105 (2019).

${ }^{3}$ S.J. Bader, R. Chaudhuri, K. Nomoto, A. Hickman, Z. Chen, H.W. Then, D.A. Muller, H.G. Xing, and D. Jena, IEEE Electron Device Lett. 39, 1848 (2018).

${ }^{4}$ A. Krishna, A. Raj, N. Hatui, O. Koksaldi, R. Jang, S. Keller, and U.K. Mishra, Phys. Status Solidi A 217, 1900692 (2020).

${ }^{5}$ Y. Gao, D. Sun, X. Jiang, and J. Zhao, J. Appl. Phys. 125, 215705 (2019).

${ }^{6}$ U. Wahl, L.M. Amorim, V. Augustyns, A. Costa, E. David-Bosne, T.A.L. Lima, G. Lippertz, J.G. Correia, M.R. da Silva, M.J. Kappers, K. Temst, A. Vantomme, and L.M.C. Pereira, Phys. Rev. Lett. 118, 095501 (2017).

${ }^{7}$ S. Nakamura, T. Mukai, M. Senoh, and N. Iwasa, Jpn. J. Appl. Phys. 31, L139 (1992).

${ }^{8}$ S. Nakamura, N. Iwasa, M. Senoh, and T. Mukai, Jpn. J. Appl. Phys. 31, 1258 (1992).

${ }^{9}$ A. Dussaigne, B. Damilano, J. Brault, J. Massies, E. Feltin, and N. Grandjean, J. Appl. Phys. 103, 013110 (2008).

${ }^{10}$ Wook Kim, A. Salvador, A.E. Botchkarev, O. Aktas, S.N. Mohammad, and H. Morcoç, Appl. Phys. Lett. 69, 559 (1996).

${ }^{11}$ Y. Arakawa, K. Ueno, A. Kobayashi, J. Ohta, and H. Fujioka, APL Mater. 4, 086103 (2016).

12 W. Götz, N.M. Johnson, D.P. Bour, M.D. McCluskey, and E.E. Haller, Appl. Phys. Lett. 69, 3725 (1996).

${ }^{13}$ M.G. Cheong, K.S. Kim, N.W. Namgung, M.S. Han, G.M. Yang, C.-H. Hong, E.-K. Suh, K.Y. Lim, H.J. Lee, and A. Yoshikawa, J. Cryst. Growth 221, 734 (2000).

${ }^{14}$ W. Götz, R.S. Kern, C.H. Chen, H. Liu, D.A. Steigerwald, and R.M. Fletcher, Mater. Sci. Eng. B 59, 211 (1999).

15 P. Kozodoy, H. Xing, S.P. DenBaars, U.K. Mishra, A. Saxler, R. Perrin, S. Elhamri, and W.C. Mitchel, J. Appl. Phys. 87, 1832 (2000).

${ }^{16}$ S. Brochen, J. Brault, S. Chenot, A. Dussaigne, M. Leroux, and B. Damilano, Appl. Phys. Lett. 103, 032102 (2013).

${ }^{17}$ R.R. Lieten, V. Motsnyi, L. Zhang, K. Cheng, M. Leys, S. Degroote, G. Buchowicz, O. Dubon, and G. Borghs, J. Phys. Appl. Phys. 44, 135406 (2011).

${ }^{18}$ K. Wittmaack, Nucl. Instrum. Methods Phys. Res. Sect. B Beam Interact. Mater. At. 64, 621 (1992).

${ }^{19}$ Probion Analysis, https://probion.fr.

${ }^{20}$ M. Levy and M.P. Sarachik, Rev. Sci. Instrum. 60, 1342 (1989).

${ }^{21}$ B.A. Hull, S.E. Mohney, H.S. Venugopalan, and J.C. Ramer, Appl. Phys. Lett. 76, 2271 (2000).

${ }^{22}$ C.H. Kuo, S.J. Chang, Y.K. Su, L.W. Wu, J.K. Sheu, C.H. Chen, and G.C. Chi, Jpn. J. Appl. Phys. 41, L112 (2002).

${ }^{23}$ M.G. Cheong, K.S. Kim, C.S. Kim, R.J. Choi, H.S. Yoon, N.W. Namgung, E.-K. Suh, and H.J. Lee, Appl. Phys. Lett. 80, 1001 (2002).

${ }^{24}$ V. Bougrov, M. Levinshtein, S. Rumyantsev, and A. Zubrilov, in Prop. Adv. Semicond. Mater. GaN AIN InN BN SiC SiGe, eds M.E.Levinshtein, S.L. Rumyantsev and M.S.Shur) John Wiley\&Sons, Inc., New York (2001), p. 7.

${ }^{25}$ S. Hautakangas, J. Oila, M. Alatalo, K. Saarinen, L. Liszkay, D. Seghier, and H.P. Gislason, Phys. Rev. Lett. 90, 137402 (2003).

${ }^{26}$ E. Litwin-Staszewska, R. Piotrzkowski, L. Dmowski, P. Prystawko, R. Czernecki, and L. Konczewicz, J. Appl. Phys. 99, 033703 (2006). 
${ }^{27}$ E. Litwin-Staszewska, T. Suski, R. Piotrzkowski, I. Grzegory, M. Bockowski, J.L. Robert, L. Kończewicz, D. Wasik, E. Kamińska, D. Cote, and B. Clerjaud, J. Appl. Phys. 89, 7960 (2001). ${ }^{28}$ D. Andiwijayakusuma, F. Ishii, and M. Saito, in Recent Dev. Comput. Sci. (Kanazawa, Japan, 17-18 Feb.), pp. 86-94.

${ }^{29}$ J. Neugebauer and C.G. Van de Walle, Phys. Rev. Lett. 75, 4452 (1995).

${ }^{30}$ Y.-J. Lin, Appl. Phys. Lett. 84, 2760 (2004).

${ }^{31}$ H. Kim and T.G. Andersson, Phys. B 5 (2001).

${ }^{32}$ G. Parish, S. Keller, S.P. Denbaars, and U.K. Mishra, J. Electron. Mater. 29, 15 (2000).

${ }^{33}$ A. Parisini and R. Nipoti, J. Appl. Phys. 114, 243703 (2013).

${ }^{34}$ S. Contreras, L. Konczewicz, R. Arvinte, H. Peyre, T. Chassagne, M. Zielinski, and S. Juillaguet, Phys. Status Solidi A 214, 1600679 (2017).

${ }^{35}$ G. Pensl, F. Schmid, F. Ciobanu, M. Laube, S.A. Reshanov, N. Schulze, K. Semmelroth, H. Nagasawa, A. Schöner, and G. Wagner, Mater. Sci. Forum 433-436, 365 (2003).

${ }^{36}$ D. Lancefield and H. Eshghi, J. Phys. Condens. Matter 13, 8939 (2001).

${ }^{37}$ A. Parisini, M. Gorni, A. Nath, L. Belsito, M.V. Rao, and R. Nipoti, J. Appl. Phys. 118, 035101 (2015). 


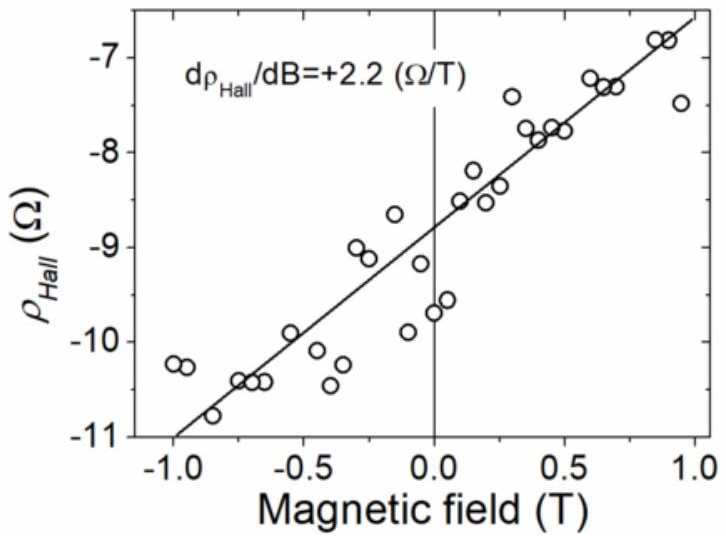




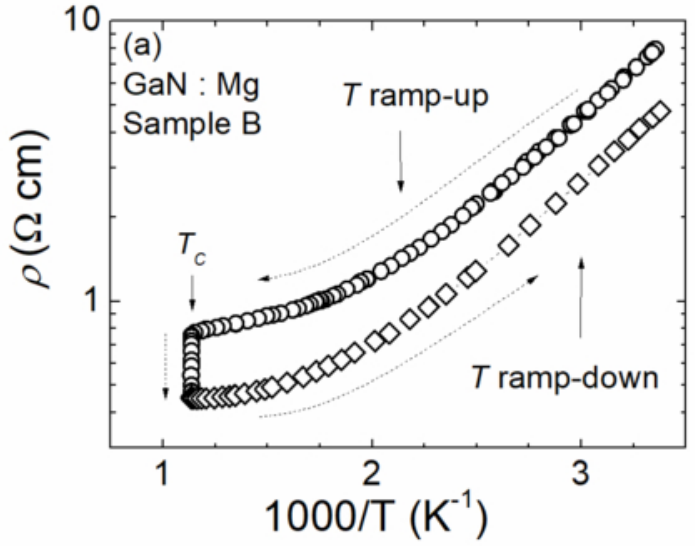




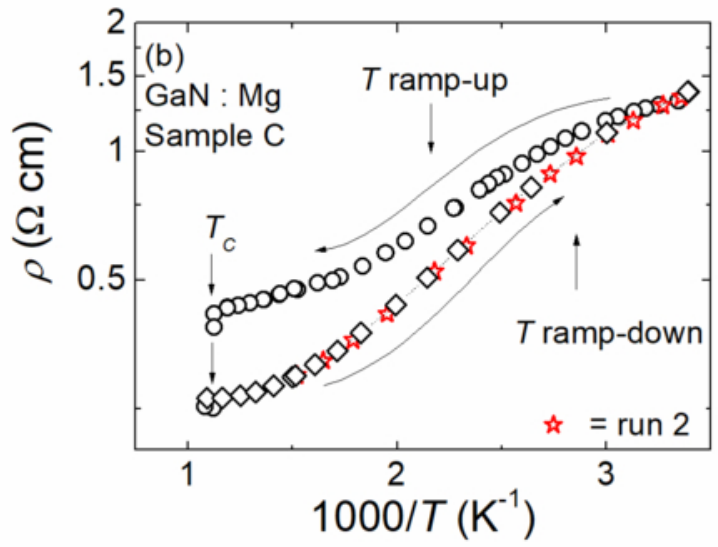




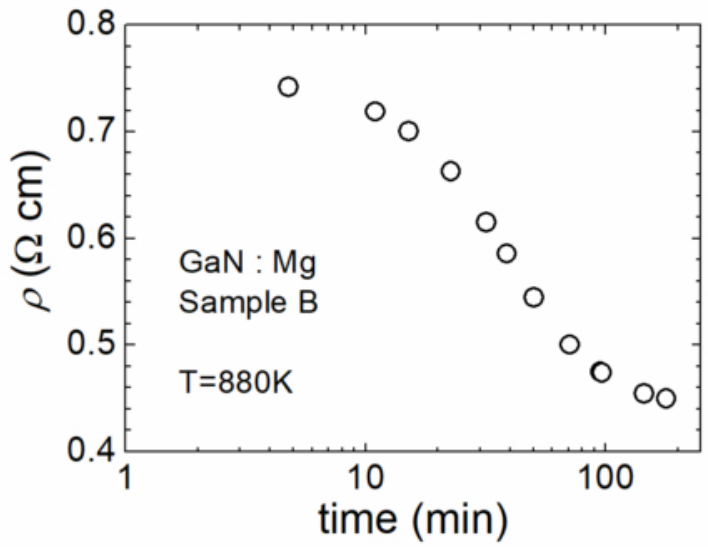




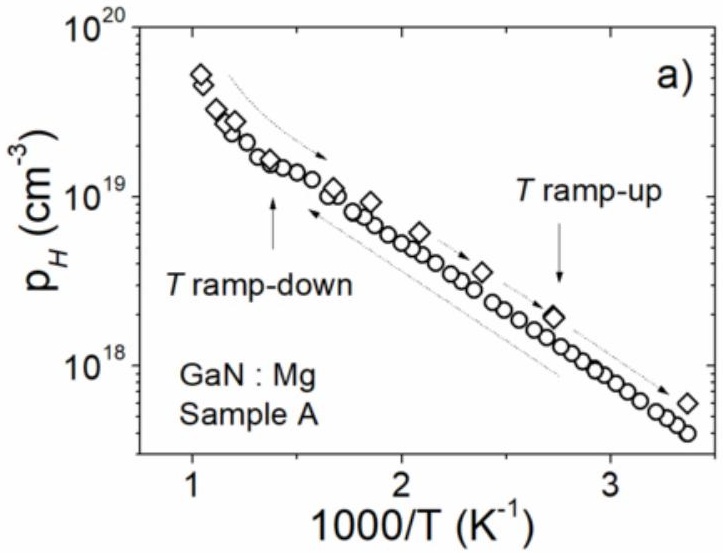




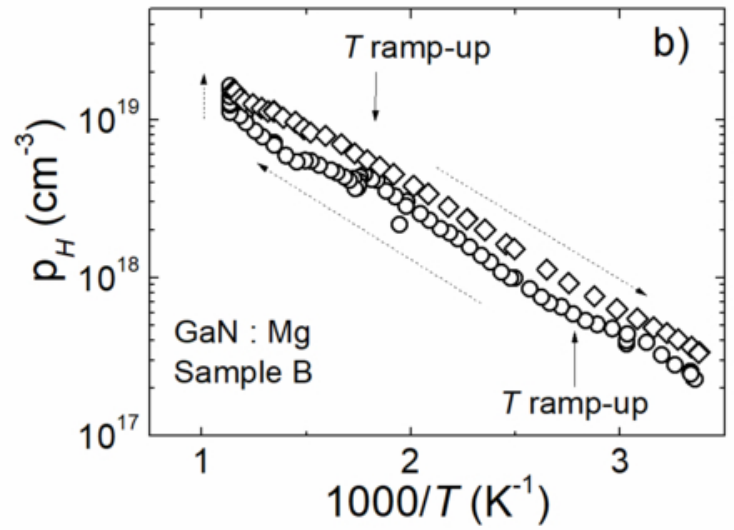




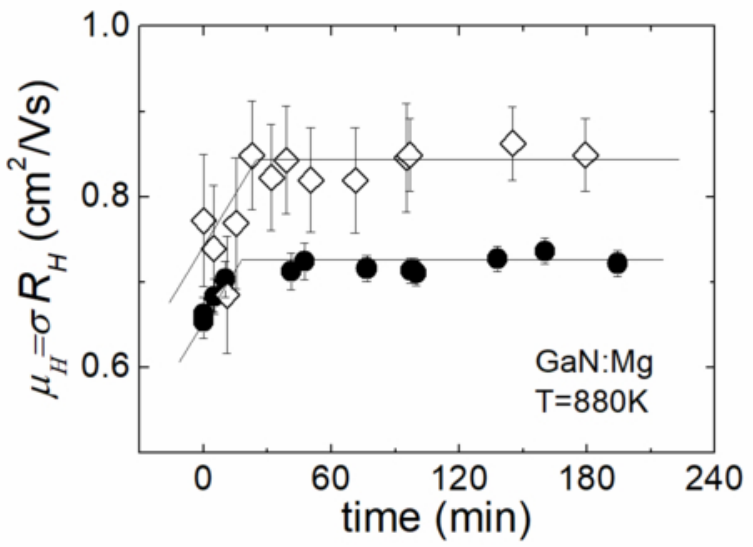




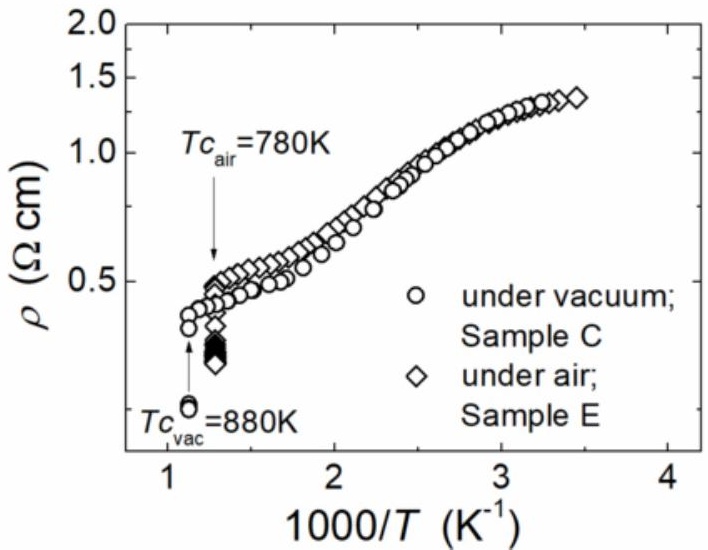




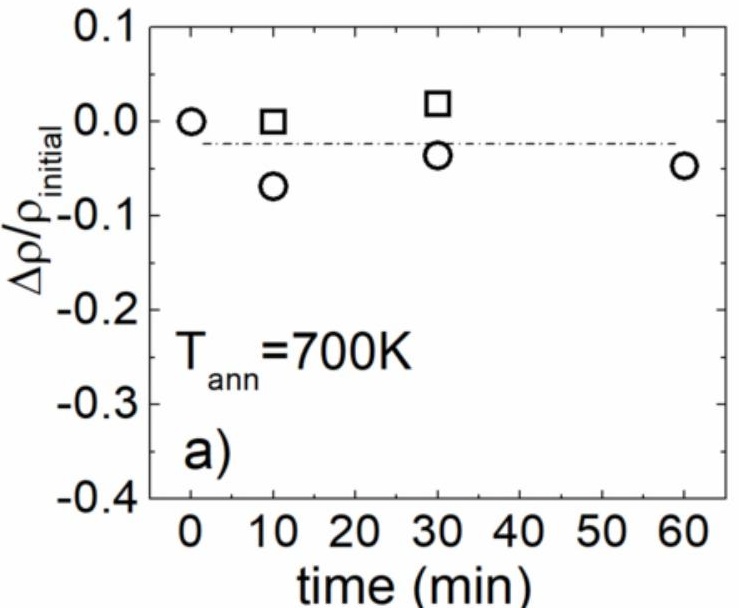




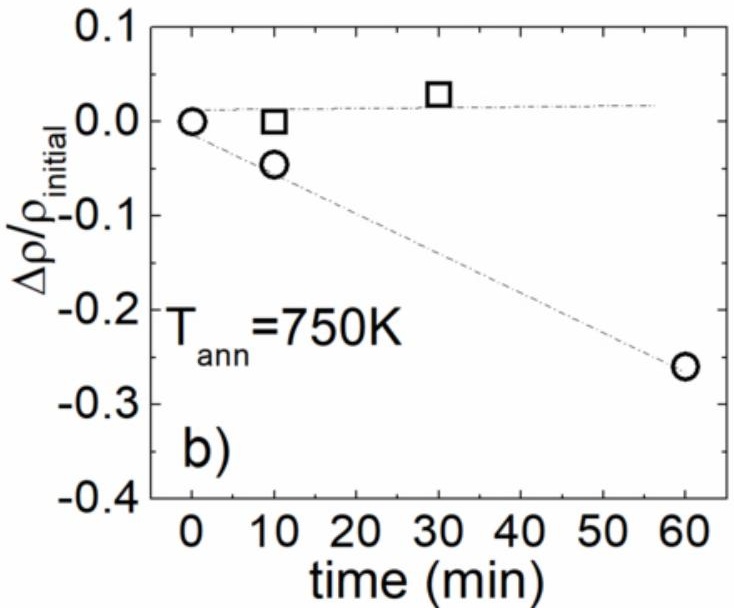




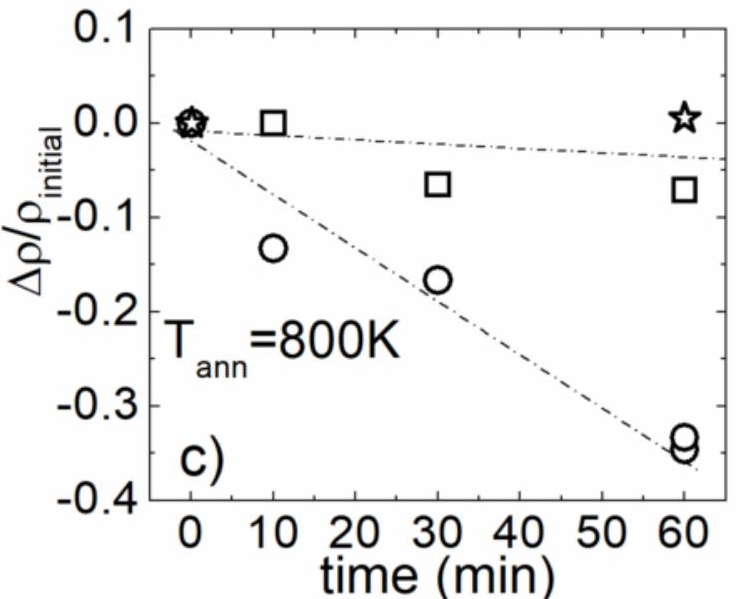




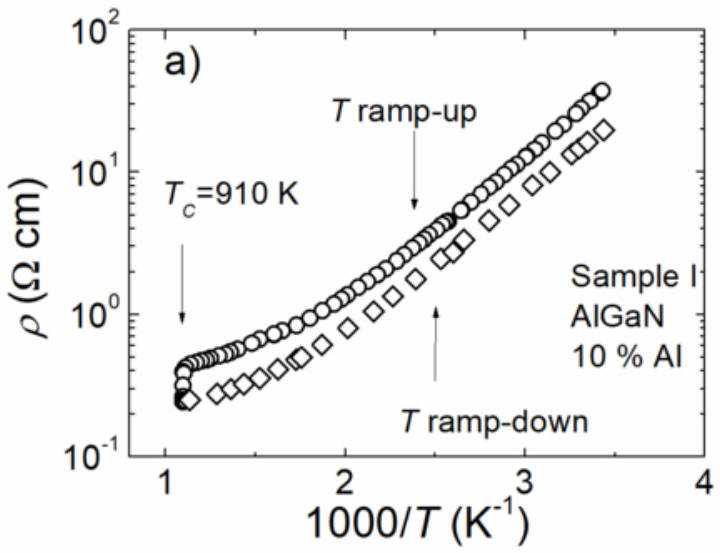




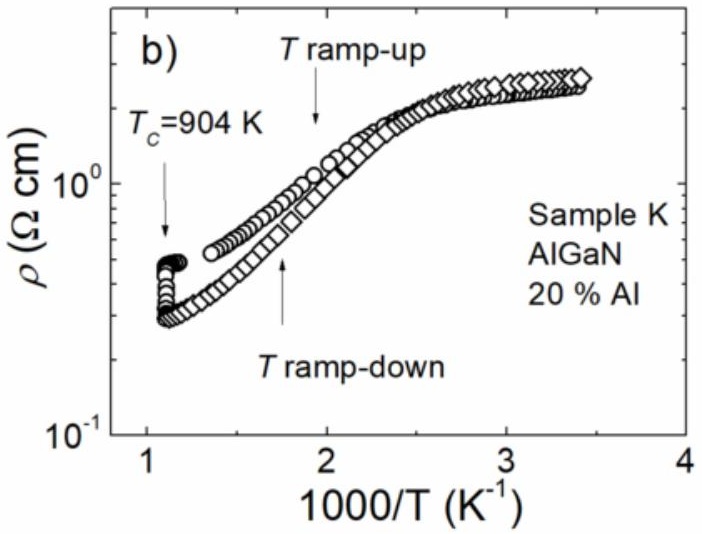




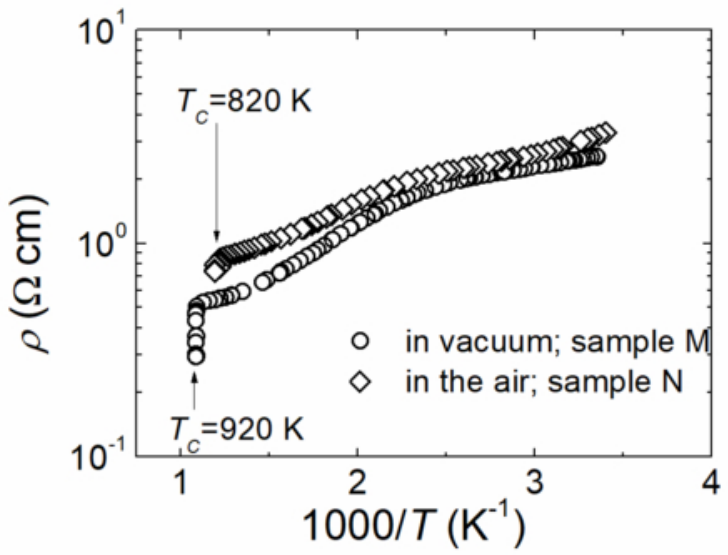




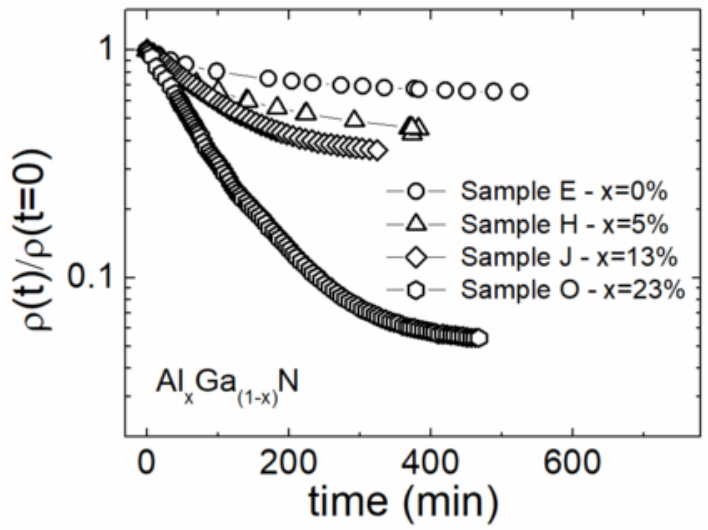




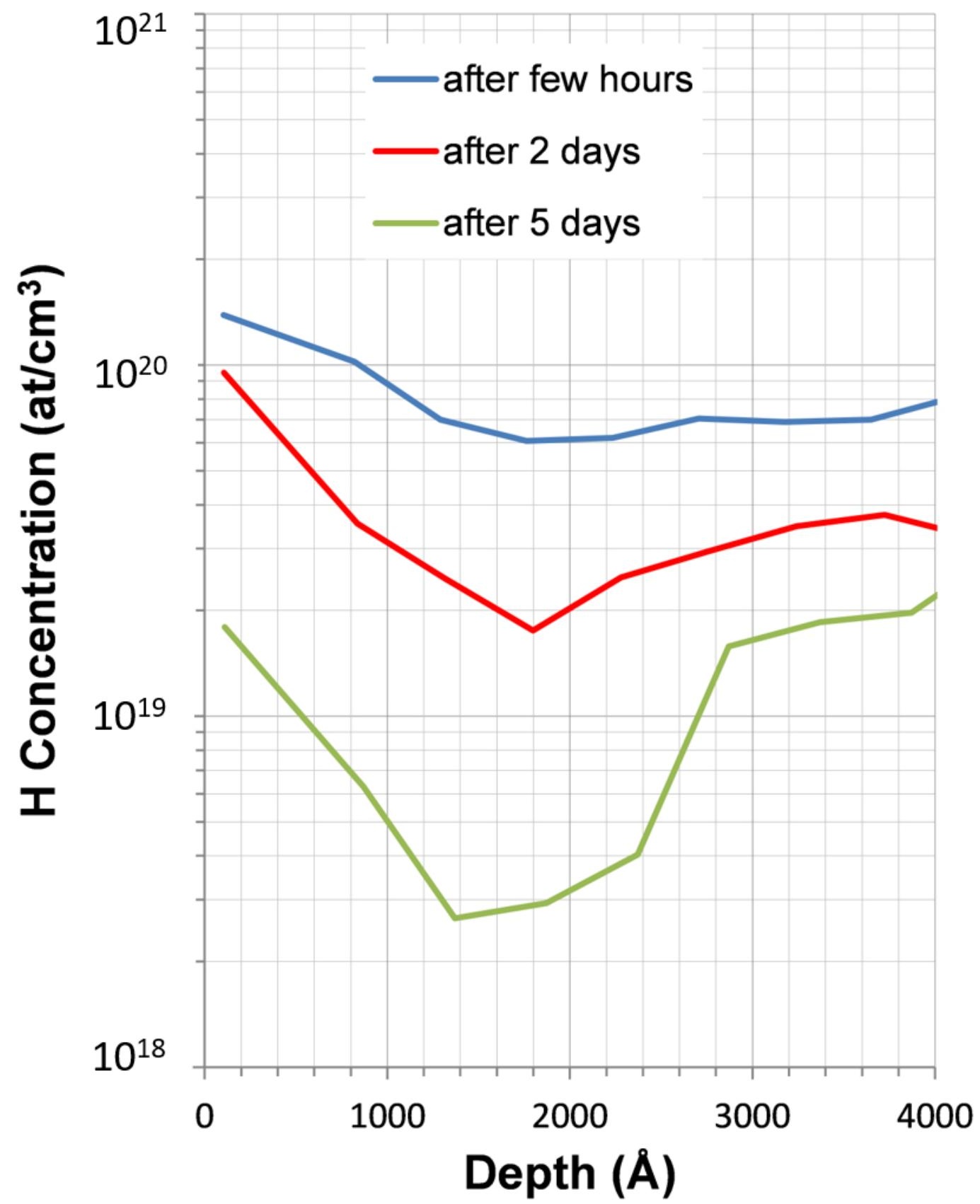




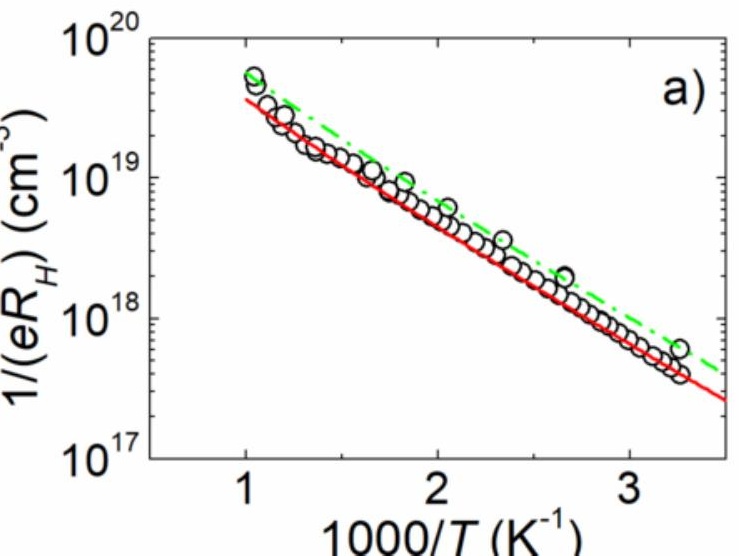




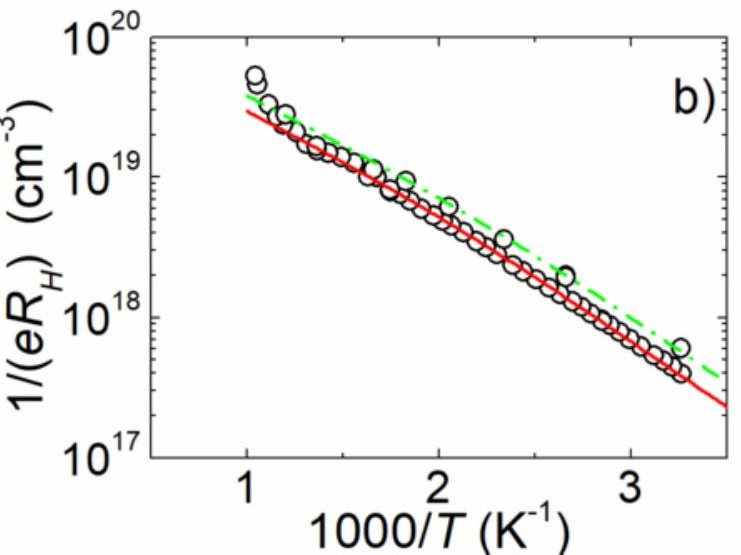




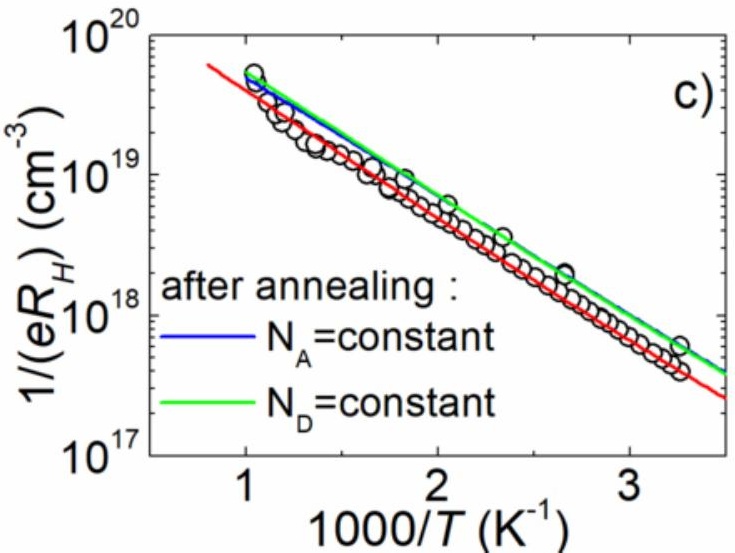




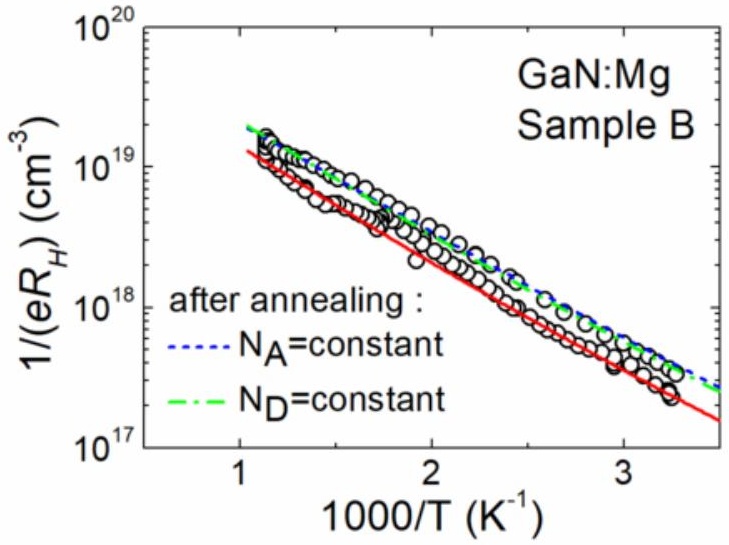




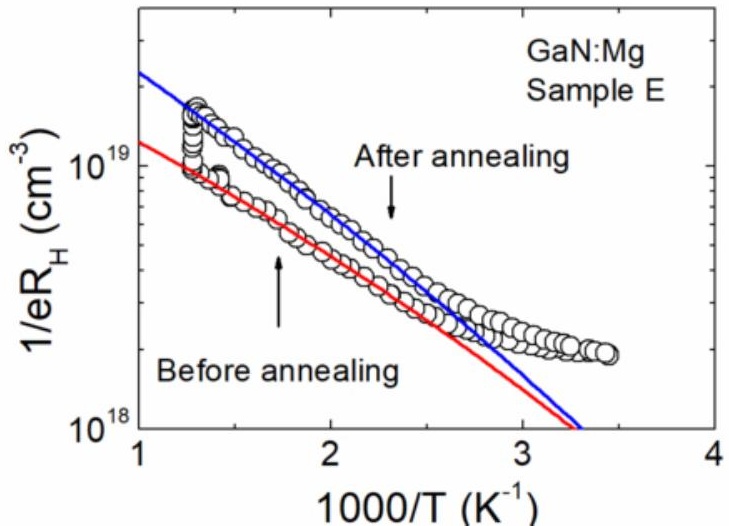

